\title{
A Novel Design and Performance Analysis of an ISM Band Antenna for Biomedical Applications
}

\author{
Abdullah Al- Faruk and Rinku Basak
}

\begin{abstract}
Biomedical application is an advancing sector of research work which permits the development of a transmission link from a living body to an extrinsic device. A microstrip patch antenna is proposed in this paper for biomedical applications. The antenna is designed to operate in the Industrial, Scientific and Medical (ISM) band $(2.4-2.4835 \mathrm{GHz})$. The thickness of the antenna is only $2.3 \mathrm{~mm}$ which implies that the antenna is reliable to operate under bent conditions. The dimension of the proposed antenna is $28.5 \mathrm{~mm} \times 28.5 \mathrm{~mm} \times 2.3 \mathrm{~mm}$. In this antenna, Copper is used as the patch material and FR-4 is used as the substrate material. Three-layer human tissue model is used to analysis the performance of the antenna. Computer Simulation Technology (CST) software is used to designed the antenna and analysis the performance parameter of the antenna such as the return loss (S11 parameter), radiation pattern, operating frequency, directivity, gain, total efficiency under normal and bent conditions on the human tissue model. Performance analysis is also observed for different substrate material, different patch material, and different types of human tissues and comparison analysis of S11 parameter for the planar and bent condition. Among all of the substrate materials, FR4 provides the good antenna performance. Finally, Specific Absorption Rate (SAR) and thermal loss are evaluated to comply with the antenna safety issues.
\end{abstract}

Keywords-Microstrip Patch Antenna; ISM Band; Bio-medical Antenna ; Specific Absorption Rate (SAR);

\section{INTRODUCTION}

Biomedical telemetry allows the assessment of physiological signals at a range, with the help of wired and wireless communications. Physiological signals are obtained

\author{
Abdullah Al- Faruk \\ American International University- Bangladesh \\ Dhaka, Bangladesh \\ E- mail: faruk.abir93@gmail.com
}

\section{Rinku Basak}

Associate Professor, Faculty of Engineering

American International University- Bangladesh

Dhaka, Bangladesh

E-mail: rinku@aiub.edu by means of appropriate transducers are used to attain physiological signals. And these physiological signals are transmitted to external running devices. Implantable medical device is one of the greatest advancement in the field of biomedical telemetry. Medical devices support millions of people worldwide [1] and biomedical antennas are playing significant roles in wireless body area network (WBAN) systems. Considering WBAN applications, on-body matched antennas must be compact size, flexible and light weight [2-3]. Now-a-days, patients do not need to stay longtime in hospital for regular check-up, instead of that wearable medical devices can be embedded in patient's body with biomedical antennas to monitor real time data. In consideration of carrying the technological development in the medical sector, remote diagnostic method plays the important role by regulating with wireless communication technology. The on-body matched antenna is turning into a dynamic component of biomedical applications [2-4].

Through the fast development of communication, the area of wireless network has become more supportive for the diagnostic and medical sector applications. A Wireless Body Area Network is a special purpose to operate various medical equipment located inside and outside the human body. It supports connectivity between different nodes of the human body with the help of implantable antenna to a remote health monitoring system through wireless communication technology. WBAN for health care diagnosing and other applications propose flexibilities and cost-saving opportunity to health care patients. WBAN offers the location independent monitoring ability and mobility of patients due to use of portable devices. By the use of RF technology, data recorded by the implanted antenna can be transmitted wirelessly to the receiving end which is used for the biomedical application. For establishing communication of WBAN via implantable antenna is always a tough task due to the miniaturized size of implantable medical devices [5-6].

There are various bands which can be considered for designing the biomedical antenna. These bands arrange a numerous frequency range for the medical application. Industrial, Scientific, and Medical (ISM), Medical Implant Communication Service (MICS), Wireless Medical Telemetry Service (WMTS) and Ultra Wide Band (UWB) are allocated for the biomedical antenna. 902-928 MHz, $2.4 \mathrm{GHz}$, and 5.7$5.8 \mathrm{GHz}$ bands are used for Industrial, Scientific and Medical (ISM) Band [7-8]. 401 to $406 \mathrm{MHz}$ frequency range is 
allocated for Medical Implant Communication Service (MICS) to support the biomedical devices [9]. 608 - 614, $1395-1400$, and $1427-1432 \mathrm{MHz}$ band spectrum is used for remote diagnosing of a patient's health in Wireless Medical Telemetry Service (WMTS) [10]. WMTS carry equipment to monitor patients' vital signs and other health parameters and components that transport the information via a radio link to a remote location, such as a nurses' location. 3.1-10.6 GHz band frequency is used in Ultra Wide Band (UWB) for a biocompatible antenna [11]. Recently, ISM band has been widely used by researchers for designing compact sized antenna with higher frequency band.

In recent times, ISM band biomedical antennas are designed with the miniaturization and modification of the antenna parameters. Literature [12] \& [13] presented a miniaturized antenna for biomedical applications for ISM band. The antenna was an updated version with fifty percent size reduction, low return loss with good performance measurements of the previous similar antenna mentioned in literature [14]. Regarding ISM band antenna, researchers have been trying to design miniaturized antenna but several parameters like Specific Absorption Rate (SAR) should be considered in terms of biomedical applications which was missing in literature [15].

This paper presented a rectangular shape patch on-body matched antenna operating in ISM band. Design improvement and performance analysis are achieved with the proposed antenna design. The design of the proposed antenna was novel and this kind of patch designing is the reason for maintenance of the novelty of the proposed antenna. The antenna gave a very good performance with this patch. The designed antenna is embedded with biocompatible layer for the safety issue. Different substrate materials are analyzed to check its versatility. SAR calculations is restrained to keep safety regulations and is followed the IEEE C95.5 and ICNIRP standard [16]. All the calculations and simulations have been prepared using CST Microwave studio. Significant parameters have been analyzed for the proposed antenna such as reflection coefficient, 3D far field, 2D far field, VSWR, radiation efficiency, the specific absorption rate for the human phantom model etc. Considering previously published literatures, this antenna can be fitted in biomedical applications for WBAN systems.

\section{MODELLING OF THE ANTENNA}

In this paper, a rectangular shaped microstrip patch antenna is presented for biomedical application. Copper is used as the ground plane and patch material. FR4 is used as the substrate material which has dielectric constant 4.3 and tangent 0.014 .
After comparing with other substrate materials, we have found that FR4 gives better results that is under ISM Band but other substrate materials did not provide the desired results under ISM Band. The substrate thickness is $1.42 \mathrm{~mm}$. Antenna size parameters are given in Table I below. Several slots are cut to maintain the antenna under resonance frequency band. Waveguide port was used in this case since it has lower dielectric loss and higher transmitting power. Input impedance of the antenna was set to $50 \Omega$. ISM band allows more flexibility. ISM band has shortest range but highest data rates. This band also reduces the wavelength with higher data rate. Another reason for choosing the ISM band for the proposed antenna is the worldwide availability.

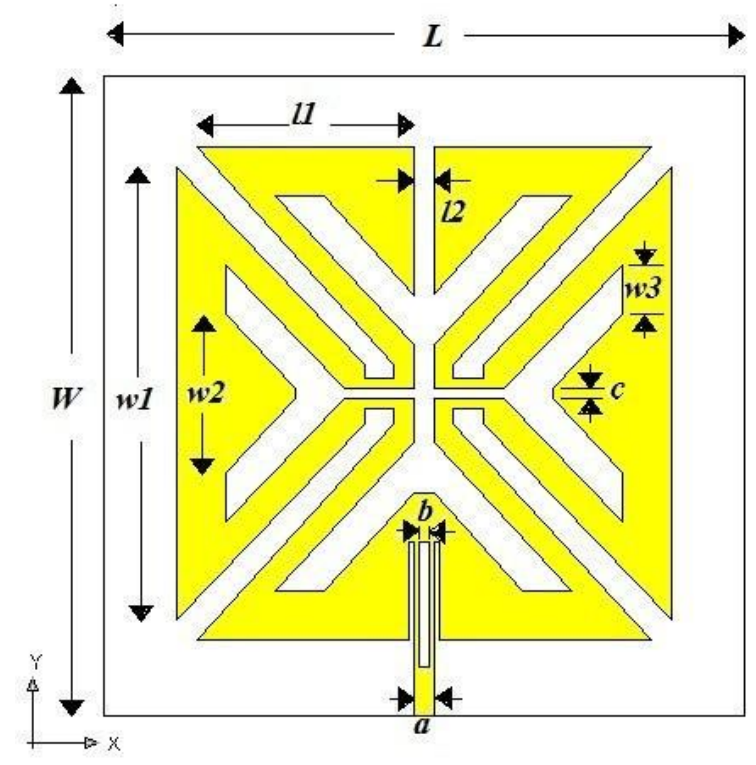

(a)

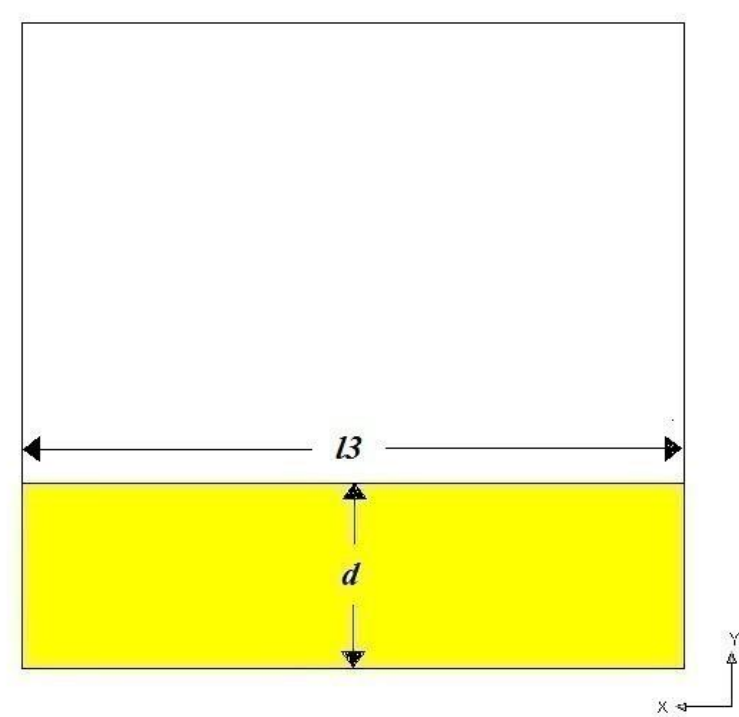

(b) 
Fig. 1. Antenna Geometric Model (a) Radiating Patch (b) Ground Plane

\section{A. Geometry of the antenna}

Fig. 1 shows the antenna model in the free space which includes the top and bottom layers of the antenna. The final dimension of this antenna is $28.50 \mathrm{x} 28.50 \mathrm{~mm}^{2}$. All simulation is done using CST Microwave Studio. After free space calculation the designed antenna is implanted on the three layer human phantom model.

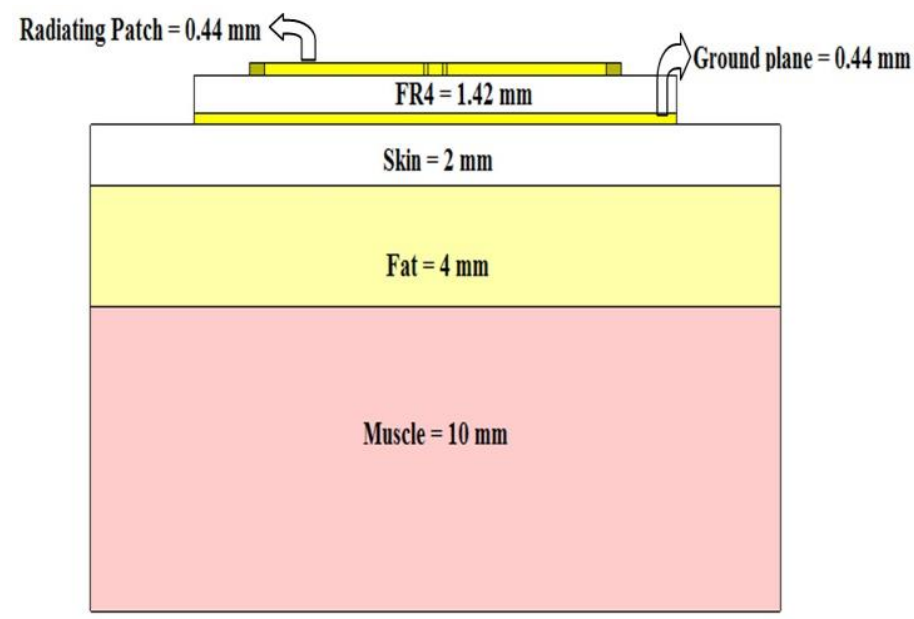

Fig. 2. Three layer (skin, fat and muscle) model geometry of the antenna

Fig. 2 shows the antenna is implanted on the three layer geometric human tissue model which includes skin, fat and muscle and Fig. 3 shows the side view of the proposed antenna on a human phantom model. The characteristic of the antenna is affected by the dielectric constant, conductivity of the skin, fat and muscle. In order to get the desired resonance frequency from the antenna, the depth of the muscle has been taken into consideration. After characterization of the antenna on the human tissue model, the result is checked and emphasized on the S11 parameter, the antenna is re-calculated so that it covers the ISM band at a resonant frequency of $2.4755 \mathrm{GHz}$. All the calculations and the antenna performance were determined on the human phantom model at CST Microwave Studio simulation environment.

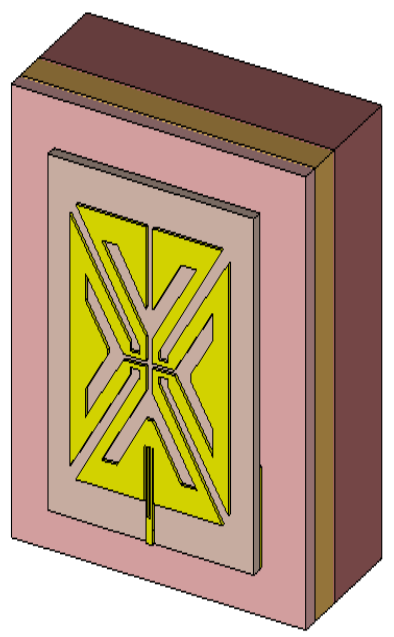

Fig. 3. Side view of the proposed antenna on human phantom model

TABLE I. Antenna Size Parameters

\begin{tabular}{|c|c|c|c|}
\hline Parameter & Value $(\mathrm{mm})$ & Parameter & Value(mm) \\
\hline$L$ & 28.50 & $w_{1}$ & 20.42 \\
\hline $\boldsymbol{W}$ & 28.50 & $w_{2}$ & 7.20 \\
\hline$l_{1}$ & 9.67 & $w_{3}$ & 2.20 \\
\hline$l_{2}$ & 0.98 & $a$ & 0.88 \\
\hline$l_{3}$ & 28.50 & $b$ & 0.40 \\
\hline$c$ & 0.64 & $d$ & 8.13 \\
\hline
\end{tabular}

\section{B. Material specification}

Copper and FR4 is used as the patch and substrate material for designing the proposed on- body matched antenna. The material specifications are given belowin Table II and III.

TABLE II. ELECTRIC PROPERTIES OF COPPER MATERIAL

\begin{tabular}{|c|c|}
\hline Parameters & Values \\
\hline Loss Tangent, tan $\delta$ & 0.025 \\
\hline Electric conductivity & $5.8 e+07[\mathrm{~S} / \mathrm{m}]$ \\
\hline Thermal conductivity & $401[\mathrm{~W} / \mathrm{K} / \mathrm{m}]$ \\
\hline
\end{tabular}




\section{B. Voltage Standing Wave Ratio (VSWR)}

TABLE III. ELECTRIC PROPERTIES OF FR4 SUBSTRATE MATERIAL

\begin{tabular}{|c|c|}
\hline Parameters & Values \\
\hline Loss Tangent, tan $\delta$ & 0.014 \\
\hline Dielectric Constant, \&r & 4.3 \\
\hline Thermal conductivity & $0.3[\mathrm{~W} / \mathrm{K} / \mathrm{m}]$ \\
\hline
\end{tabular}

\section{Simulated Results}

In this section the simulated results of the proposed antenna on three layer human tissue model are shown. S11 parameter, far field region, Voltage Standing Wave Ratio, radiation efficiency, the Specific absorption rate for the human phantom model are analyzed.

\section{A. S11 parameter or Reflection Coefficient}

S11 parameter is also called reflection coefficient. It shows that how much power is being radiated from the antenna. Fig. 4 shows that $\mathrm{S} 11$ parameter is $-38.03 \mathrm{~dB}$ at resonance frequency $2.4755 \mathrm{GHz}$ which satisfies the ISM band.

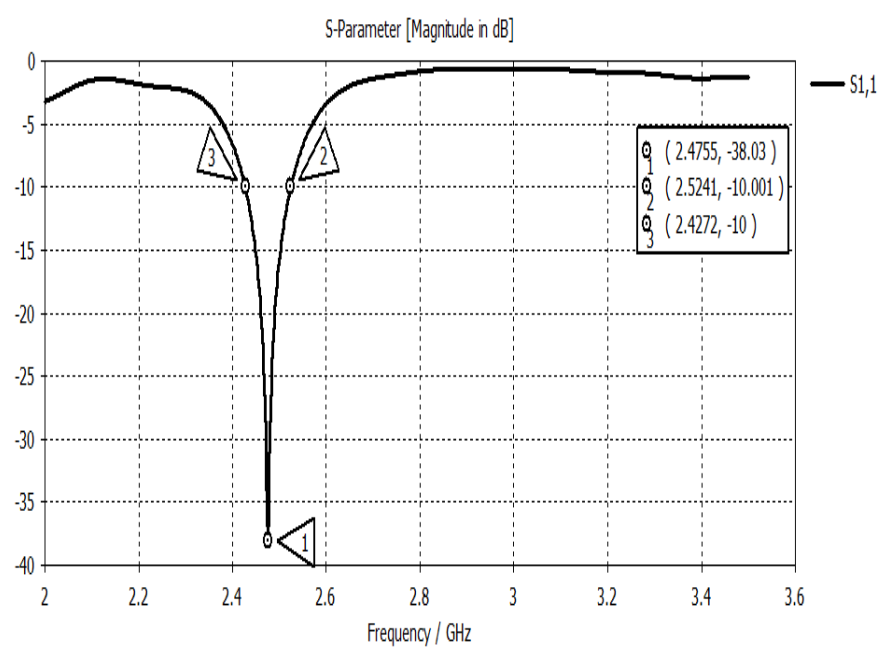

Fig. 4. S11 parameter or reflection coefficient of the antenna on human tissue model

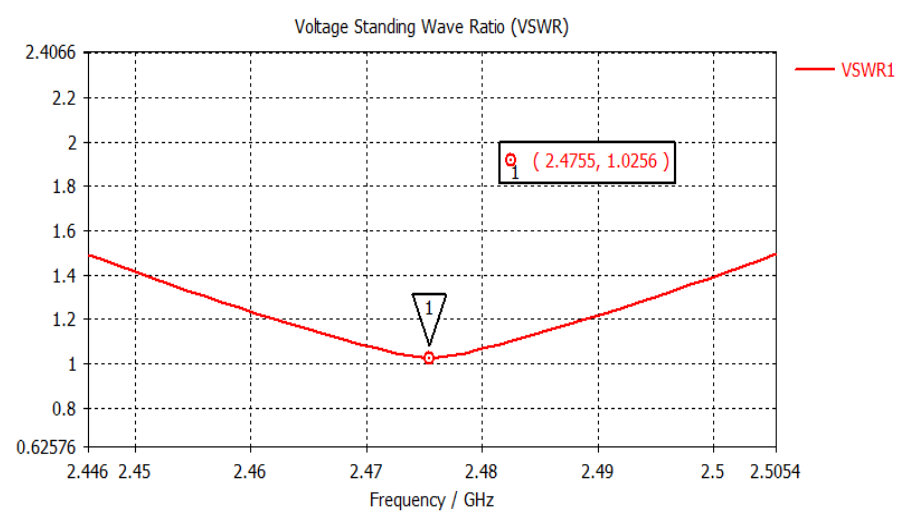

Fig. 5. VSWR values of the antenna on human tissue model

Fig. 5 shows the voltage standing wave ratio value is 1.0256 at resonance frequency $2.4755 \mathrm{GHz}$ which is less than 2 and gives a very good output.

\section{Far Field region}

Fig. 6 shows the three dimensional view of far field region of the antenna on human tissue model. The directivity of the antenna is $3.893 \mathrm{dBi}$ and total radiation efficiency is $-13.23 \mathrm{~dB}$.

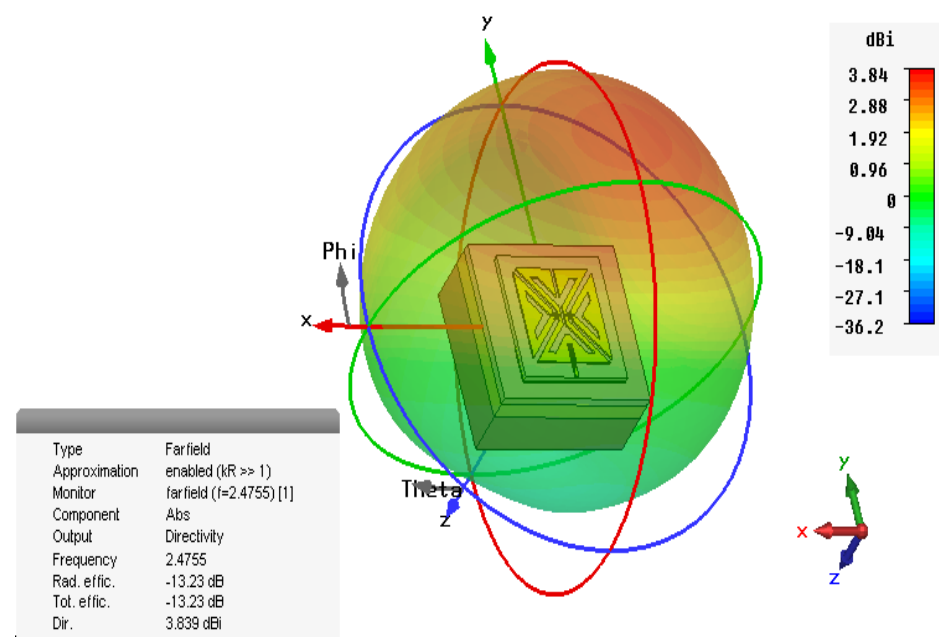

Fig. 6. 3D view of Far Field region of the antenna on human tissue model

Fig. 7 shows the two dimensional view of far field region of the antenna on human tissue model. Fig. 7 shows that the antenna has its main lobe magnitude of $3.84 \mathrm{~dB}$ centered at 167 degree and the angular width is around 124.6 degree. 
Farfield Directivity Abs (Phi=90)

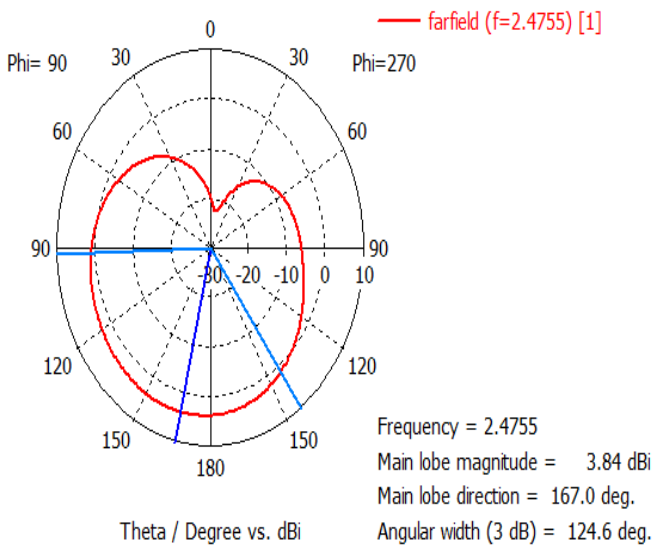

Fig. 7. 2D view of Far Field region of the antenna on human tissue model

\section{Efficiency}

Fig. 8 shows efficiency of the antenna on human tissue model. The radiation efficiency is $-13.22875 \mathrm{~dB}$ and total radiation efficiency is $-13.22945 \mathrm{~dB}$ of the antenna.

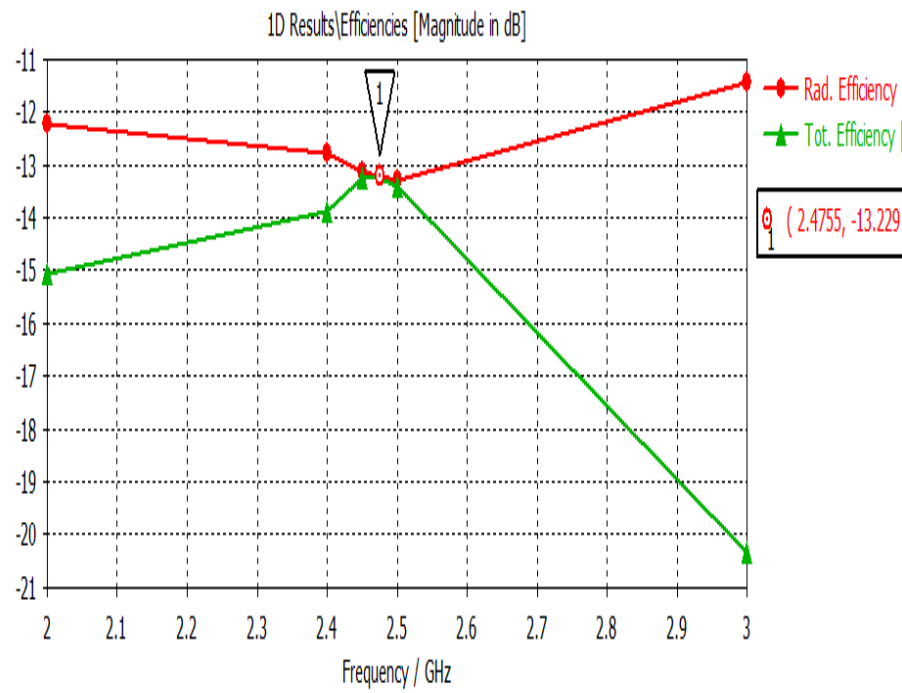

Fig. 8. Total efficiency and Radiation efficiency of the antenna

\section{E. Specific Absorption Rate}

The measuring rate at which radio frequency or RF energy is absorbed by a living body from the measuring source is known SAR (specific absorption rate). Fig. 9 shows the value of SAR is $0.1065 \mathrm{~W} / \mathrm{Kg}$ for $1 \mathrm{~g}$ avg at resonance frequency $2.4755 \mathrm{GHz}$ which fulfill the requirements of ICNIRP and FCC guidelines regarding Specific absorption rate [17].

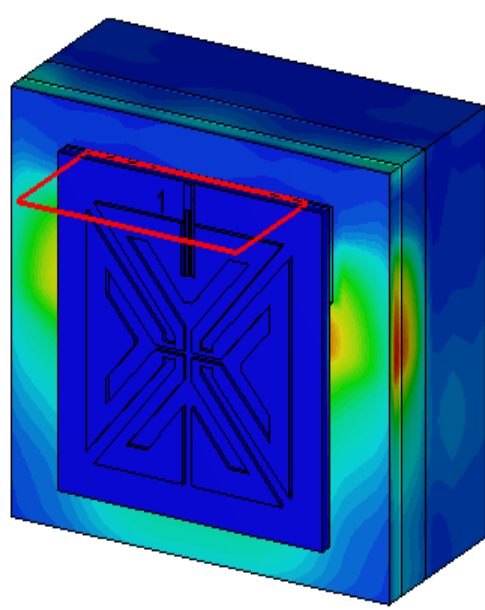

\section{SAR $(f=2.4755)[1](1 \mathrm{~g})($ peak $)$}

3D Maximum [W/kg]: 0.1065

Fig. 9. Specific absorption rate of the antenna on human tissue model

\section{F. Antenna under bending anlysis}

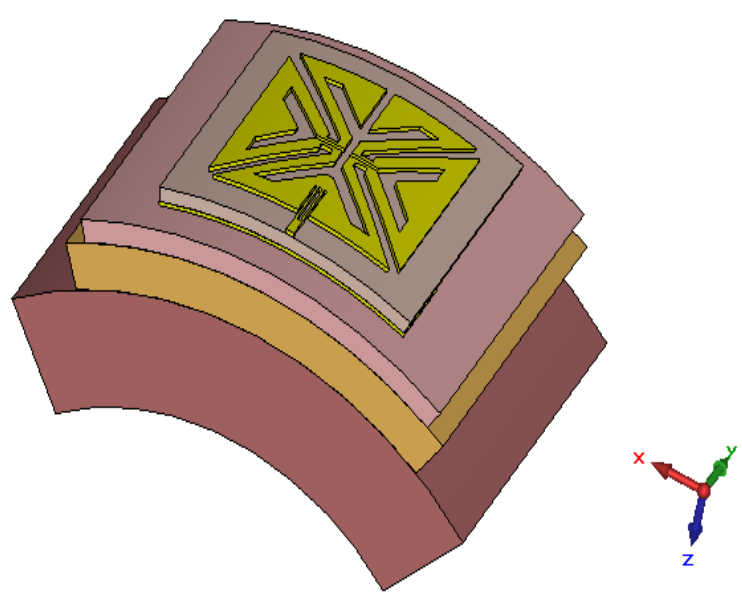

Fig. 10. Antenna under bend test

Fig. 10 shows the performance of the antenna under bending condition. This antenna properties approve it for bending test on human phantom model. The return loss or S11 parameter covers the ISM band of the antenna in bent analysis. When the antenna is bended arround $30 \mathrm{~mm}$ cylinder, S11 parameter is $18.629 \mathrm{~dB}$ at $2.444 \mathrm{GHz}$. When the antenna is bended arround $40 \mathrm{~mm}$ cylinder, $\mathrm{S} 11$ parameter is $-16.113 \mathrm{~dB}$ at $2.3952 \mathrm{GHz}$ which is very close to ISM band. The bend simulation result of the antenna is given in the comparison analysis section.

\section{COMPARISON ANLYSIS}

\section{A. Comparison Analysis for different substrate material}

Fig. 11 shows the performance of the antenna for different substrate materials on human tissue model. It demonstrates that Rogers RO3006 is near the ISM band and 
Roger RT6010, Teflon are outside the ISM band. FR4 is obtained under the ISM band and increased the antenna performance.

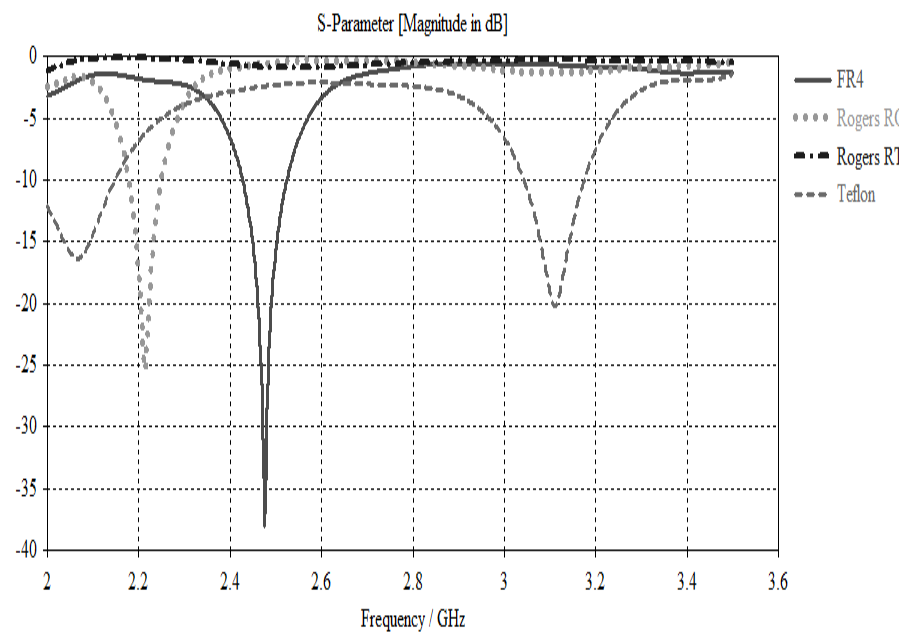

Fig. 11. S11 parameter of the antenna using different substrate materials

\section{B. Comparison Analysis for different patch material}

Fig. 12 shows the performance of the antenna for different substrate materials on human tissue model. It demonstrates that Nickel is near the ISM band and Aluminum is outside the ISM band. But Copper, Gold, Platinum are obtained under the ISM band and increased the antenna performance.

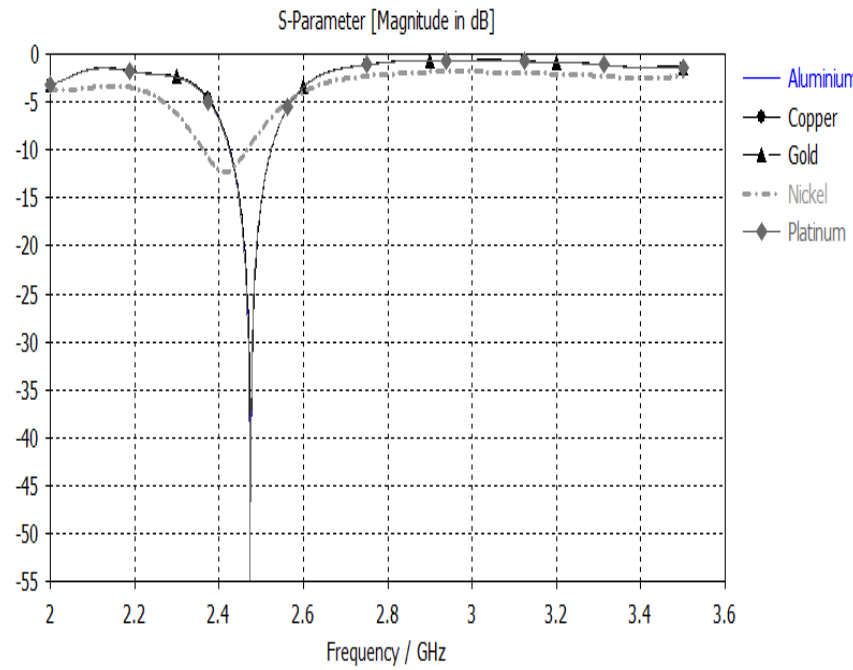

Fig. 12. S11 parameter of the antenna using different patch materials

\section{Comparison Analysis for different human tissue}

Fig. 13 shows the performance of the antenna for different human tissue model. The comparison analysis for different human tissue was obtained from the CST microwave studio software. Antenna is first set on bone, brain, muscle and stomach; after that the performance has been analyzed. That is how the results was obtained from different human tissues.
Fig. 13 shows that each human tissue model covers the ISM band and gives good S11 value.

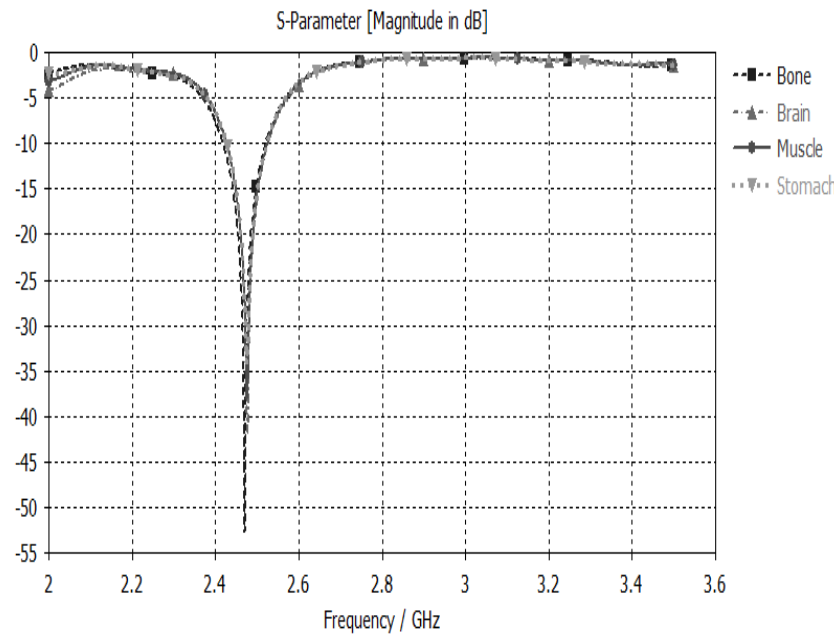

Fig. 13. S11 parameter of the antenna using different human tissue

\section{Comparison Analysis for planar and bent condition}

Fig. 14 shows the comparison analysis of the antenna between the planar and bent condition. In planar condition the S11 parameter covers the ISM band and S11 is -38.035 $\mathrm{dB}$ at resonance frequency $2.4755 \mathrm{GHz}$. But in bent condition S11 parameter is shifted a little portion. S11 is 18.629 at resonance frequency $2.44 \mathrm{GHz}$ where the antenna is bended around $30 \mathrm{~mm}$ cylinder and $\mathrm{S} 11$ parameter covers the ISM band in bent condition. Again $\mathrm{S} 11$ is -16.113 at resonance frequency $2.3952 \mathrm{GHz}$ where the antenna is bended around $40 \mathrm{~mm}$ cylinder and $\mathrm{S} 11$ parameter is very close to the ISM band.

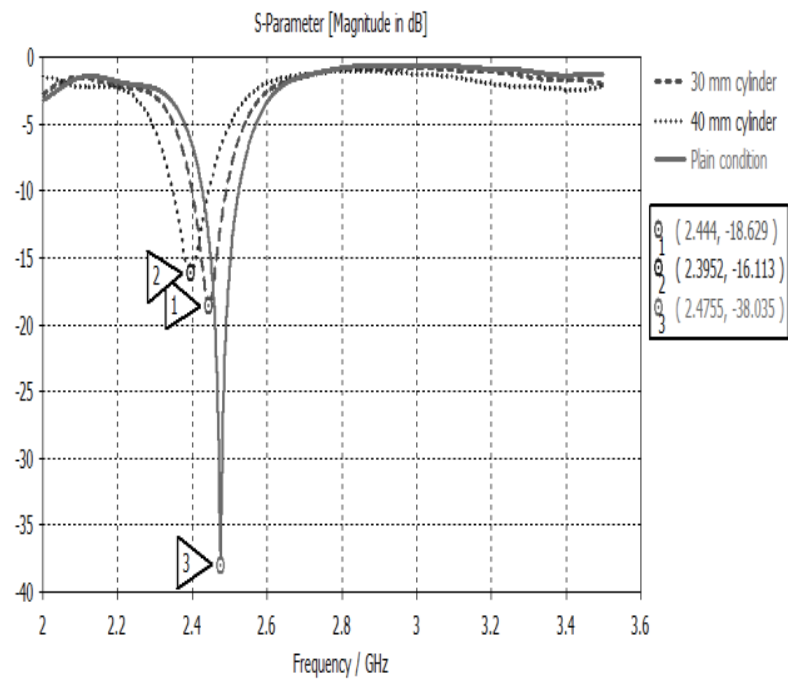

Fig. 14. Comparison of S11 parameter for planar and bent condition

\section{Conclusion}


A rectangular shape microstrip patch antenna operating at Industrial, Scientific, and Medical (ISM) Band is presented for biomedical application. The performance of the antenna is analyzed for three layer geometric human tissue model. All the performance measurements such as return loss or reflection coefficient, VSWR, 2D and 3D far field radiation pattern, radiation efficiency, specific absorption rate are analyzed with the antenna on the human tissue model. Comparison analysis in different substrate materials is also measured and FR4 gives better antenna performance all of them. Overall the results show that, this antenna will contribute an enormous anticipation in future biomedical research.

\section{REFERENCE}

[1] Shubair, Raed M., et al. "Novel miniature wearable microstrip antennas for ISM-band biomedical telemetry." Antennas \& Propagation Conference (LAPC), 2015 Loughborough. IEEE, 2015.

[2] Haque E, Mahmuda S, Ahmed F. A capsule-like flexible multiband antenna for WBAN applications. InRegion 10 Conference, TENCON 2017-2017 IEEE 2017 Nov 5 (pp. 1614-1619). IEEE

[3] Biswas, A., Islam, A.J., Ahammad, K.T. and Barua, B., 2017, December. A miniaturized on-body matched antenna design and its performance evaluation at ISM band. In Electrical Information and Communication Technology (EICT), 2017 3rd International Conference on (pp. 1-6). IEEE.

[4] Biswas, A., Islam, A.J., Al-Faruk, A. and Alam, S.S., 2017, February. Design and performance analysis of a microstrip line-fed on-body matched flexible UWB antenna for biomedical applications. In Electrical, Computer and Communication Engineering (ECCE), International Conference on (pp. 181-185). IEEE.

[5] Movassaghi, Samaneh, et al. "Wireless body area networks: A survey." IEEE Communications Surveys \& Tutorials 16.3 (2014): 16581686.

[6] Zhu, Xiao-Qi, Yong-Xin Guo, and Wen Wu. "A compact dual-band antenna for wireless body-area network applications." IEEE Antennas and Wireless Propagation Letters 15 (2016): 98-101.

[7] Kiourti, Asimina, and Konstantina S. Nikita. "Miniature scalpimplantable antennas for telemetry in the MICS and ISM bands: design, safety considerations and link budget analysis." IEEE Transactions on Antennas and Propagation60.8 (2012): 3568-3575.

[8] Yilmaz, Tuba, Tutku Karacolak, and Erdem Topsakal. "Characterization and testing of a skin mimicking material for implantable antennas operating at ISM band (2.4 GHz-2.48 GHz)." IEEE Antennas and Wireless Propagation Letters 7 (2008): 418-420.

[9] Savci, Huseyin S., et al. "MICS transceivers: regulatory standards and applications [medical implant communications service]." SoutheastCon, 2005. Proceedings. IEEE. IEEE, 2005

[10] Gieras, Izabella A. "The proliferation of patient-worn wireless telemetry technologies within the US healthcare environment." Information Technology Applications in Biomedicine, 2003. 4th International IEEE EMBS Special Topic Conference on. IEEE, 2003.

[11] Kiminami, Katsuki, Akimasa Hirata, and Toshiyuki Shiozawa. "Doublesided printed bow-tie antenna for UWB communications." IEEE antennas and wireless propagation letters 3.1 (2004): 152-153.
[12] Al Islam, N., Aleef, T.A., Arafat, U. and Islam, A.J., 2016, May. Design improvement and performance comparison of an existing slot dipole bendable antenna for biomedical applications. In Informatics, Electronics and Vision (ICIEV), 2016 5th International Conference on (pp. 508-512). IEEE.

[13] Al Islam, N., Abrar, A.T., Arafat, U., Islam, A.J. and Hoque, R., 2015, December. Design and performance measurement of an in-body implantable miniaturized Slot Dipole rectangular patch antenna for biomedical applications. In Advances in Electrical Engineering (ICAEE), 2015 International Conference on (pp. 59-63). IEEE.

[14] Scarpello, Maria Lucia, et al. "Design of an implantable slot dipole conformal flexible antenna for biomedical applications." IEEE Transactions on Antennas and Propagation 59.10 (2011): 3556-3564.

[15] T. A. Aleef and A. Biswas, "Design and measurement of a flexible implantable stripline-fed slot antenna for biomedical applications," 2016 3rd International Conference on Electrical Engineering and Information Communication Technology (ICEEICT), Dhaka, 2016, pp. 1-5.

[16] Keshvari, J., et al. "Large scale study on the variation of RF energy absorption in the head \& brain regions of adults and children and evaluation of the SAM phantom conservativeness." Physics in Medicine \& Biology 61.8 (2016): 2991.

[17] Hardell, Lennart, and Cindy Sage. "Biological effects from electromagnetic field exposure and public exposure standards." Biomedicine \& Pharmacotherapy 62.2 (2008): 104-109.

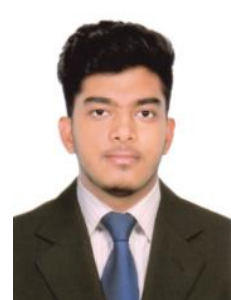

Mr. Abdullah Al- Faruk has received his Bachelor of Science in Electrical and Electronic Engineering (EEE) from American International UniversityBangladesh (AIUB) on January, 2016. Now he is continuing his Master of Science in Electrical and Electronic Engineering (EEE) in AIUB. After completing his Bachelor degree, he started serving as a Lecturer, Dept. of EEE, Port City International University, Chittagong from April, 2016 to December, 2016. After that, now he is serving as a Lecturer, Dept. of EEE, European University of Bangladesh from January, 2017 to till the date. His research interest includes Bio-medical Antenna, Bio- signal Processing etc.

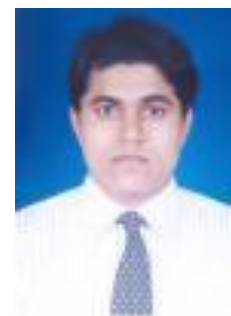

Mr. Rinku Basak has received his B. Sc. Engineering (EEE) degree from Knulna University of Engineering \& Technology (KUET) in 2004. He received his M. Sc. Engineering (EEE) degree from Bangladesh University of Engineering \& Technology (BUET) in 2007. Currently he is working as an Associate Professor, Faculty of Engineering in AIUB. He is a member of IEEE, USA and IEB, Bangladesh. His research interests are on high power and high speed VCSELs, Violet LASER, Blue LASER, True Blue LASER, Red LASAER, SOA, EDFA and Microwave Antenna. 
